\title{
Controle de Endemias: Responsabilidades Municipal \\ e Regional
}

Maria Rita Donalísio*

Nota-se no Brasil, a completa falta de controle de doenças como a malária, cólera, leishmaniose, dengue, tuberculose, meningites, tracoma, entre outras.

Nos últimos anos, as cifras da malária beiram os 600.000 casos anuais ( $95 \%$ na região Norte e Centro Oeste), sem que os serviços de saúde tenham qualquer impácto na disseminação da doença.

A Cólera se espalhou pelo continente americano a partir de 1991 e atualmente no Brasil, já foi incorporada como uma doença endêmica, principalmente em regiões pobres do Nordeste e Norte do país.

O Dengue pulsa em epidemias explosivas, extremeadas pela transmissão endêmica em várias regiões brasileiras. Atualmente no $\mathrm{CO}, \mathrm{NE}$ e $\mathrm{SE}$ epidemias de Febre Hemorrágica do Dengue já são realidades no Rio de Janeiro (1991 e 1995), Ceará (1994). Os vetores e o vírus se disseminam sem cerimônia por vários estados brasileiros.

A Leishmaniose toma fôlego em São Paulo, onde são identificados focos de transmissão autóctone em vários municípios do estado.

O Tracoma tem sido diagnosticado no estado de São Paulo e em outros estados brasileiros mostrando que a dimensão do problema não foi sequer avaliada.

São alguns exemplos de enfermidades endêmico-epidêmicas que circulam pelo país com grande impacto na morbi-mortalidade.

Certamente, as epidemias e endemias tem raizes históricas e sociais, cujos principais determinantes são as precárias condições de vida da população, as formas de ocupação do espaço e a falta de acesso aos serviços e equipamentos urbanos.

* Profa. do Departamento de Medicina Preventiva e Social da FCM-UNICAMP 
Porém, o papel das instituições de saúde no controle das doenças epidêmicas é de grande impacto e relevância.

Em épocas passadas, campanhas sanitárias específicas lograram o controle, e mesmo a eliminação de várias doenças no território nacional, como a febre amarela urbana, a varíola e mais recentemente a poliomielite, mostrando com radicalidade a capacidade dos serviços.

As ações médico-sanitárias têm grande potencial de interferência na situação epidemiológica do país. Este é o campo da saúde pública, parte do nosso objeto de trabalho. Estão aí nossas responsabilidades teóricas e operacionais.

Com que instrumentos enfrentar hoje, as endemias e epidemias que circulam pelo país e particularmente pelo estado de São Paulo?

A Constituição de 1988 ampliou o dever do Estado na área da saúde, com objetivos de aumentar a cobertura, distribuir melhor os recursos è facilitar o controle social. Consolidou em forma de lei, as propostas de descentralização e municipalização das ações médico-sanitárias, que já vinham sendo implantada, com dificuldades, em vários municípios brasileiros. São conquistas da sociedade civil e de profissionais de saúde em direção à Reforma Sanitária no país.

A descentralização das ações médico-assistenciais e da gestão local são discussões mais aprofundadas e explícitas. Enquanto as propostas de descentralização da vigilância epidemiológica e controle de endemias não ficaram bem claras, Não se definiu como serão garantidos e repassados os recursos (montagem de infra-estrutura e manutenção de programas) para os municípios desempenharem estas "novas" responsabilidades.

A municipalização é uma bandeira de importância capital para a garantia de acesso e da ampliação de cobertura dos serviços de saúde, da qualidade das ações e do seu caráter público.

O palco onde se concretiza a epidemia é a cidade. As medidas terão alí seu destino.

Sem dúvida as instâncias municipais são locais privilegiados para se decidir as "maneiras de fazer", para se coordenar e avaliar as ações das equipes de controle de doenças. Porém, os vetores não reconhecem as divisas oficiais dos municípios e com freqüência, medidas isoladas de controle de endemias não trazem impacto duradouro.

No caso das doenças endêmico-epidêmicas a descentralização das ações devem ser estruturadas com cuidado. Assumem grande importância, os níveis regionais e macro-regionais (estadual) de atuação.

$\mathrm{Na}$ esfera regional, os Escritórios Regionais de Saúde (Ersa) e a SUCEN são instâncias estratégicas para a articulação de programas de controle de vetores para a articulação epidêmicas. Suas atribuições fundamentais, definidas em vários documentos oficiais deveriam ser de "articuladores" do controle de enfermidades, apoio às atividades de treinamento das equipes locais, além de organização de discussões técnicas e elaboração de diagnósticos regionais". 
Atualmente os níveis regionais estão sucateados e paralizados, empobrecidos e isolados. Pouco interferem nos riscos de disseminação de doenças, nem mesmo suprem os vazios deixados pelas experiências de municipalização, abandonadas pelas prefeituras desinteressadas. Apesar dos grandes esforços pessoais e da militância de técnicos, mal pagos e com péssimas condições de trabalho.

No estado de São Paulo, as instituições regionais que controlam as doenças não trabalham de forma integrada. As áreas de abrangência regionais não coincidem, apesar de exercerem funções complementares e muitas vezes sobrepostas. Estas distorções dificultam as ações de controle de doenças e combate de vetores.

Para a eficácia das ações de vigilância, são fundamentais os Laboratórios de Saúde Pública (Adolfo Lutz), sem os quais, a vigilância epidemiológica e a identificação etiológica das doenças não se viabilizam. Cabe ao Estado manter estes serviços de referência, equipá-los, repensar a estrutura de funcionamento e os papéis dos laboratórios locais, regionais e central no Estado.

São unidades que deveriam manter vínculo mais estreito com as instâncias regionais, cuja atuação na área de investigação e retaguarda aos municípios estaria vinculada às ações regionais de controle de doenças.

Nenhuma municipalização terá sucesso no controle de endemias e epidemias se o nível regional não estiver forte, bem equipado e com legitimidade para coordenar o combate às endemias na região.

Desta maneira, fica registrada a necessidade de se definir os papéis das diversas esferas institucionais (local, regional, federal) para a viabilização de programas de controle de endemias e epidemias, cuja programação ultrapassa as fronteiras locais.

Definir com clareza as atribuições das diversas instâncias institucionais e integrá-las.

Outra questão fundamental é a garantia de investimentos e repasse de recursos às diversas instâncias de controle de endemias, para que possam exercer estes papéis.

Isto significa o financiamento honesto e estável para treinamento e investimento em recursos humanos, equipamentos, informatização, material educativo. Condições de trabalho.

Contudo, não se trata somente de disponibilidade e descentralização de recursos se estes não estiverem vinculados à estratégias Regionais e MacroRegionais bem definidas. Planos articulados, com atribuições específicas para as diversas esferas institucionais (local, regional, estadual), que enfrente o controle de endemias,e tenham impacto na morbi-mortalidade.

Os municípios manteriam suas equipes de trabalho sob coordenação local, definindo prioridades e modos de atuar, porém estariam vinculados à diretrizes mais gerais, para garantir a coerência, a cronologia e a organicidade do plano de controle de endemias na região. 
As diretrizes das estratégias de combate às doenças na região deveriam ser discutidas em fóruns regionais, com a participação dos municípios, das instâncias regionais de vigilância de doenças e vetores e dos laboratórios de saúde pública. $\mathrm{O}$ impacto e a eficácia das medidas norteariam as diretrizes, guiando as operações. 